\title{
Maternal and perinatal outcomes in women with eclampsia by mode of delivery at Riley mother baby hospital: a longitudinal case-series study
}

Koech Irene ${ }^{1}$, Poli Philippe Amubuomombe ${ }^{1,2^{*}}$ (D), Richard Mogeni ${ }^{1}$, Cheruiyot Andrew ${ }^{2}$, Ann Mwangi ${ }^{3}$ and Orang'o Elkanah Omenge ${ }^{1,2}$

\begin{abstract}
Background: Eclampsia, considered as serious complication of preeclampsia, remains a life-threatening condition among pregnant women. It accounts for $12 \%$ of maternal deaths and $16-31 \%$ of perinatal deaths worldwide. Most deaths from eclampsia occurred in resource-limited settings of sub-Saharan Africa. This study was performed to determine the optimum mode of delivery, as well as factors associated with the mode of delivery, in women admitted with eclampsia at Riley Mother and Baby Hospital.

Methods: This was a hospital-based longitudinal case-series study conducted at the largest and busiest obstetric unit of the tertiary hospital of western Kenya. Maternal and perinatal variables, such as age, parity, medications, initiation of labour, mode of delivery, admission to the intensive care unit, admission to the newborn care unit, organ injuries, and mortality, were analysed using the Statistical Package for the Social Sciences software version 20.0. Quantitative data were described using frequencies and percentages. The significance of the obtained results was judged at the $5 \%$ level. The chi-square test was used for categorical variables, and Fisher's exact test or the Monte Carlo correction was used for correction of the chi-square test when more than $20 \%$ of the cells had an expected count of less than 5 .
\end{abstract}

Results: During the study period, 53 patients diagnosed with eclampsia were treated and followed up to 6 weeks postpartum. There was zero maternal mortality; however, perinatal mortality was reported in $9.4 \%$. Parity was statistically associated with an increased odds of adverse perinatal outcomes ( $p=0.004, \mathrm{OR}=9.1,95 \% \mathrm{Cl}=2.0-40.8)$ and caesarean delivery $(p=0.020, \mathrm{OR}=4.7,95 \% \mathrm{Cl}=1.3-17.1)$. In addition, the induction of labour decreased the risk of adverse outcomes ( $p=0.232, \mathrm{OR}=0.3,95 \% \mathrm{Cl}=0.1-2.0)$.

Conclusion: There is no benefit of emergency caesarean section for women with eclampsia. This study showed that induction of labour and vaginal delivery can be successfully achieved in pregnant women with eclampsia. Maternal and perinatal mortality from eclampsia can be prevented through prompt and effective care.

Keywords: Maternal and perinatal outcomes, Eclampsia, Mode of delivery, Resource-limited settings

\footnotetext{
* Correspondence: philippe_poli@yahoo.fr

${ }^{1}$ Reproductive Health, Moi Teaching\& Referral Hospital, PO Box 3-30100, Nandi road, Eldoret, Kenya

${ }^{2}$ Department of Reproductive Health, Moi University School of Medicine, P. O. Box 4606-30100, Eldoret, Kenya

Full list of author information is available at the end of the article
}

(C) The Author(s). 2021 Open Access This article is licensed under a Creative Commons Attribution 4.0 International License, which permits use, sharing, adaptation, distribution and reproduction in any medium or format, as long as you give appropriate credit to the original author(s) and the source, provide a link to the Creative Commons licence, and indicate if changes were made. The images or other third party material in this article are included in the article's Creative Commons. licence, unless indicated otherwise in a credit line to the material. If material is not included in the article's Creative Commons licence and your intended use is not permitted by statutory regulation or exceeds the permitted use, you will need to obtain permission directly from the copyright holder. To view a copy of this licence, visit http://creativecommons.org/licenses/by/4.0/ The Creative Commons Public Domain Dedication waiver (http://creativecommons.org/publicdomain/zero/1.0/) applies to the data made available in this article, unless otherwise stated in a credit line to the data. 


\section{Background}

Eclampsia is among the most common causes of maternal and perinatal mortality and morbidities. It refers to the occurrence of one or more seizures and/or unexplained coma before, during and after birth irrespective of one's history of hypertensive disorders, including preeclampsia [1-3]. The condition has been recognized and described for years despite the general lack of understanding of the aetiology of the disease. To date, eclampsia is considered as complication of severe preeclampsia because the majority of affected pregnant women (approximately 84\%) have hypertensive disorders, and $16 \%$ of them have normal blood pressures [3]. In lowand middle-income countries (LMICs), sub-Saharan Africa included nearly $17.9 \%$ of women with eclampsia and other hypertensive disorder-related complications during pregnancy (stroke, coagulopathies). Furthermore, eclampsia is among the leading causes of intensive care unit (ICU) admission [4, 5]. The disease has been extensively studied [1-6], and the evidence has recommended prompt delivery to reduce maternal and perinatal mortality and morbidity [6]. However, little has been done regarding the maternal and perinatal outcomes by mode of delivery in the particular context of resource-limited settings. Therefore, this study was performed to determine the mode of delivery in women with eclampsia in the largest tertiary hospital of western Kenya.

\section{Methods}

This was a hospital-based longitudinal case-series study, which consecutively recruited pregnant and postpartum women diagnosed with eclampsia in a one-year period at the Riley Mother and Baby Hospital (RMBH). The $\mathrm{RMBH}$ is located within Moi Teaching and Referral Hospital, the second largest national hospital of Kenya. The inclusion criteria were any women diagnosed with eclampsia during pregnancy and postpartum period between June 2019 and June 2020. All patients enrolled into the study were followed up to 6 weeks postpartum.

\section{Diagnostic criteria}

The diagnostic criteria were onset of convulsions and/or unexplained loss of consciousness in pregnant and postpartum mothers with a negative malaria test and no previous history of convulsive disorders prior to pregnancy.

The test for protein in urine used dipstick for all participants followed by urinalysis to rule out urinary tract infection. Proteinuria and elevated blood pressure (BPs) were not diagnostic criteria for eclampsia, considering that women with negative proteinuria and normal blood pressure can develop eclampsia. By using the dipstick, patients' results were classified as follows: trace $=0.1 \mathrm{~g} / \mathrm{l}$, 1 plus $(1+)=0.3 \mathrm{~g} / \mathrm{l}, 2$ plus $(2+)=1.0 \mathrm{~g} / \mathrm{l}, 3$ plus $(3+)=$ $3.0 \mathrm{~g} / \mathrm{l}$, and 4 plus $(4+)=10.0 \mathrm{~g} / \mathrm{l}$. Patients' BPs were recorded as $<140 / 90 \mathrm{mmHg}$, considered as normal and $\geq$ $140 / 90 \mathrm{mmHg}$ as per definition of hypertension in pregnancy after the 20th week of gestational. The initial BPs before any administration of drugs during convulsions was considered as accurate.

In addition, conditions such meningitis, hypoglycaemic coma and/or alcoholic coma, which could confuse the diagnosis of eclampsia, were ruled out through the patients' history, physical examination and laboratory investigations.

\section{Clinical presentation and data collection}

In majority of cases, eclampsia is preceded by features of preeclampsia. Therefore, the variables collected included symptoms of the disease such as convulsion, epigastric pain, dyspnoea, coma, palpitation, lower limb oedema, headache, blurred vision, and elevated blood pressure.

The patients with a confirmed diagnosis of eclampsia were interviewed. Data on maternal demographics, clinical characteristics, outcomes and perinatal outcomes were collected. Maternal demographic included maternal age, education level, marital status, occupation, geographic residence location, and health insurance coverage.

Clinical characteristics included last menstrual period to determine the gestational age, history of pregnancy loss, previous history of eclampsia and/ or preeclampsia, and parity. Based on their parity, patients were classified as nulliparous, multiparous, and grand multiparous. In this study, multiparous was defined as a patient who has had 4 births or less (live or stillbirth), at $\geq 28$ weeks gestational, whereas grand multiparous was defined as a patient who has had $\geq 5$ births at $\geq 28$ weeks gestational regardless the outcome.

In addition, variables on comorbidities were also collected. These included diabetes mellitus, chronic hypertension, hyperthyroid disease, renal disease, coagulopathy, human immunodeficiency virus/acquired immunodeficiency syndrome, venous thromboembolism, anaemia, malnutrition, and mental illness), and treatment prior to or during pregnancy.

The study was interested in medication during antenatal care period, mostly antihypertensive for those who could have chronic hypertension or preeclampsia, and the treatment the patients received during eclamptic seizures. These included magnesium sulfate (MgSO4); antihypertensive mainly labetalol or hydralazine, and nifedipine (adalate); corticosteroids for foetal lungs maturity. The full regimen of magnesium sulfate was given to all patients, which included a loading dose of $4 \mathrm{~g}$, followed by $1 \mathrm{~g}$ hourly for 24-h maintenance therapy following delivery. The MgSO4 toxicity was closely monitor through patients' vital signs (oxygen saturation, deep 
tendon reflexes, and level of consciousness) and serum magnesium levels.

Intravenous labetalol was given, $20 \mathrm{mg}$ for all patients with blood pressures (BPs) of $\geq 160 / 110 \mathrm{mmHg}$ or the mean arterial pressure (MAP) of $\geq 125 \mathrm{mmHg}$ every 20 min until the BPs dropped down to $<150 / 100 \mathrm{mmHg}$, then labetalol was shifted to nifedipine $20 \mathrm{mg}$ three times daily till normalization of BPs. All women with gestational age $<34$ weeks were given at least single dose of $12 \mathrm{mg}$ of dexamethasone intramuscular, before induction of labour or C-section as per RMBH protocol.

For patients who were transferred from peripheral facilities, the information regarding the medications was recorded as well. Following the national guidelines, those patients received at least a loading dose of magnesium sulfate either $10 \mathrm{~g}$ intramuscular (5 $\mathrm{g}$ in each buttock) or $4 \mathrm{mg}$ intravenous over $20 \mathrm{~min}$, and $20 \mathrm{mg}$ of nifedipine before being transferred to RMBH for further management. The 24-h maintenance therapy of magnesium sulfate was completed at RMBH.

During the course of treatment, the study grouped the patients in 2, those who received anticonvulsant (magnesium sulfate) only, and those who received multiple drugs including antihypertensive, anticonvulsants, and corticosteroids. Patients who were admitted to intensive care unit also received either diazepam or ketamine according to Moi Teaching and Referral Hospital ICU protocol.

The variables related to antenatal care attendance and facility attended, mode of admission, mode of delivery (vaginal or caesarean section delivery, indication of Csection was recorded), and mode of initiation of labour were recorded.

Regarding antenatal care visit, the study identified 2 groups: one consisted of pregnant mothers who attended antenatal clinic regardless of the frequency, and another group consisted of pregnant women who did not attend ANC visit. Those who attended antenatal care visit were grouped in 6 levels of national care grouping system, including health dispensaries (level 2), health centre (level 3 ), sub-county (level 4), which represent primary care level. County hospitals (level 5), known as district hospitals, representing secondary care level; and national teaching and referral hospitals (level 6), represent the tertiary care level [7]. Private facilities were included whereas community services (level 1 ) were excluded.

Induction of labour (IOL) was defined as the process of artificially stimulating the uterus to start labour. The study used different methods of IOL, which included misoprostol 25 micrograms either sub-lingual or vaginal, cervical insertion of Foley catheter size 16 or 18 ballooned with $80 \mathrm{ml}$ normal saline, and combination of misoprostol 25 micrograms sub-lingual and cervical insertion of Foley catheter. These three methods of induction of labour are approved by the RMBH protocol. The IOL involved exclusively pregnant women admitted with a confirmed diagnosis of eclampsia, but without established labour. The decision of induction was influenced by a reassuring foetal status on electronic foetal monitor (cardiotocogram), and maternal status. However, there were patients referred at immediate postpartum, either for recurrent eclamptic seizures or prematurity. For patients who delivered at $\mathrm{RMBH}$ through $\mathrm{C}$-section, the presence of paediatrician was documented as per RMBH protocol.

\section{Maternal and perinatal outcomes}

Maternal outcomes of interest included the occurrence of $\geq 1$ of the following complications: stroke, acute kidney injuries (AKI), HELLP syndrome (Haemolysis, Elevated Liver enzymes, and Low Platelet), heart failure, pulmonary oedema, coagulopathy, ICU admission, and mortality or recovery within 6 weeks postdelivery.

The haemorrhagic stroke, life-threatening complication of preeclampsia and eclampsia was ruled out in few patients who had recurrent eclamptic seizures or status eclampticus, neurological deficits, and prolonged coma. The CT scan was used to diagnose the haemorrhagic stroke. The tests for renal function were performed to all participants. The diagnosis of AKI was based on the serum creatinine $>80 \mathrm{mmol} / \mathrm{l}$. In addition, laboratory tests such full haemogram, abnormal peripheral blood smear (intravascular haemolysis), increased serum bilirubin $(\geq 20.5 \mu \mathrm{mol} / \mathrm{L}$ or $\geq 1.2 \mathrm{mg} / 100 \mathrm{~mL})$ and elevated LDH levels (>600 units/L (U/L) were used for the diagnosis of HELLP syndrome. However, the nadir platelet count alone during the course of the disease was also considered as diagnosis of HELLP syndrome. Therefore, patients classified into complete and incomplete HELLP syndrome [8], based on laboratory results described above.

Perinatal outcomes of interest were defined by the occurrence $\geq 1$ of the following complications: stillbirths (fresh or macerated), Apgar score $<7$ at five minutes, newborn unit (NBU) admission, and mortality or recovery within 7 days following delivery. The study was interested on the 5-min Apgar score to determine newborn's neurologic outcome. Immediately after delivery, either vaginally or through $\mathrm{C}$-section, all newborns were appropriately assessed by the primary nurse or midwife and paediatrician to determine the need for admission to nursery. Every baby born from eclamptic mother outside $\mathrm{RMBH}$ was appropriately assessed on admission to determine whether nursery admission was required. In addition, newborns were classified in 4 groups based on their birth weights: < $1000 \mathrm{~g}, 1000 \mathrm{~g}-1500 \mathrm{~g}, 1600 \mathrm{~g}$ $2400 \mathrm{~g}$, and $2500 \mathrm{~g}-400 \mathrm{~g}$. 
The mode of delivery was defined as the dependent variable. The primary outcome was defined by the occurrence of $\geq 1$ adverse maternal and perinatal outcomes indicated above. The secondary outcome was defined by recovery or persistence of maternal complications 6 weeks postdelivery and 7 days following birth for newborns.

Authors received ethical approval to conduct the study. All patients enrolled to the study provided a written informed consent. Six weeks' postdelivery period of follow up was completed for all patients. Follow up was conducted during hospitalization and after discharge from the ward for each patient. During follow up, the study was particularly interested on either improvement or worsening condition of each patient vital signs, laboratory tests, and the status of the newborn. The appointment schedules were given they of discharging the patient from ward, on basis of the treating doctors and captured by the research assistants.

\section{Data analysis}

The data were analysed using IBM SPSS software package version 20.0. (Armonk, NY: IBM Corp). Categorical data are described as frequencies and percentages, while continuous data are described as ranges, means, standard deviations and medians. The Kolmogorov-Smirnov test was used to verify the normality of the distribution of quantitative data. The significance of the obtained results was judged at the $5 \%$ level. The chi-square test was used for categorical variables to compare differences between groups based on their outcomes. Monte Carlo correction was used to improve the accuracy of the $p$ value for the chi-square analysis when more than $20 \%$ of the cells had an expected count of less than 5 . The odds ratio and 95\% confidence interval (CI) for maternal adverse outcomes were calculated using logistic regression.

\section{Results}

During the study period (June 2019 to June 2020), 53 pregnant and postpartum women were admitted with a diagnosis of eclampsia. Maternal socio-demographics can be seen in Supplementary Table 1.1, and clinical characteristics can be seen in Supplementary Table 2.1. Maternal blood pressures and laboratory results are see in supplementary Table 2.2. Supplementary Table 2.3 represents the management of mothers admitted with eclampsia during the study period.

\section{Maternal and perinatal outcomes}

Table 1 represents maternal and perinatal outcomes. There was no maternal death; however, $5.7 \%$ of mothers were admitted to the ICU. Additionally, $20.8 \%$ of patients had true HELLP) syndrome while
Table 1 Maternal and perinatal outcomes

\begin{tabular}{|c|c|c|}
\hline Outcome & No. & $\%$ \\
\hline \multicolumn{3}{|l|}{ Maternal outcome } \\
\hline PPH & 0 & 0.0 \\
\hline Death & 0 & 0.0 \\
\hline ICU admission & 3 & 5.7 \\
\hline Acute kidney injury (AKI) & 8 & 15.1 \\
\hline Incomplete HELLP syndrome & 6 & 11.3 \\
\hline Complete HELLP syndrome & 11 & 20.8 \\
\hline Haemorrhagic stroke & 1 & 1.9 \\
\hline Recovery from the disease & 53 & 100.0 \\
\hline Sequelae & 0 & 0.0 \\
\hline On follow up 6 weeks postdelivery & 0 & 0.0 \\
\hline \multicolumn{3}{|l|}{ Perinatal outcome } \\
\hline \multicolumn{3}{|l|}{ Death } \\
\hline Yes & 5 & 9.4 \\
\hline No & 48 & 90.6 \\
\hline \multicolumn{3}{|l|}{ Birth weight } \\
\hline$<1000 \mathrm{~g}$ & 4 & 7.5 \\
\hline $1000 \mathrm{~g}-1500 \mathrm{~g}$ & 17 & 32.1 \\
\hline $1600 \mathrm{~g}-2400 \mathrm{~g}$ & 24 & 45.3 \\
\hline $2500 \mathrm{~g}-4000 \mathrm{~g}$ & 8 & 15.1 \\
\hline \multicolumn{3}{|l|}{ NBU admission } \\
\hline Yes & 18 & 34.0 \\
\hline No & 35 & 66.0 \\
\hline \multicolumn{3}{|l|}{ Stillbirth } \\
\hline NA & 48 & 90.6 \\
\hline Fresh & 3 & 5.7 \\
\hline Macerated & 2 & 3.8 \\
\hline \multicolumn{3}{|l|}{ Score $\geq 7$} \\
\hline NA & 5 & 7.5 \\
\hline Yes & 37 & 69.8 \\
\hline No & 11 & 20.8 \\
\hline
\end{tabular}

$P P H$ postpartum haemorrhage, ICU intensive care unit, NBU newborn unit, $N A$ not applicable, HELLP elevated liver enzymes and low platelet

11.3\% had incomplete HELLP syndrome; 15.1\% others had acute kidney injury (AKI); and 1.9\% developed stroke (Table 1). All patients recovered from the disease within 6 weeks postdelivery of follow up, including follow up after discharge from hospital.

Regarding perinatal outcomes, $34.0 \%$ of newborns were admitted to the newborn unit (NBU). Mortality was reported in $9.4 \%$ of cases, and $7.5 \%$ were fresh stillbirths. The majority of newborns (73.6\%) were born with a good Apgar score of $>7$ at $5 \mathrm{~min}$, whereas only $20.8 \%$ of newborns had an Apgar score $<7$ at $5 \mathrm{~min}$. The score was not applied for $7.5 \%$ of stillbirths. 
The socio-demographic and clinical characteristics were analysed to determine factors that could be associated with the mode of delivery in pregnant women with eclampsia. The results reported in Table 2 show that socio-demographic factors, including maternal age, occupation, health insurance coverage, and geographic location of residence, were not found to be associated with the mode of delivery, even after adjustments were made for confounders. However, low maternal education level increased the odds of caesarean delivery 8 -fold ( $p=0.029 .95 \% \mathrm{CI}=1.2-51.5)$.

In addition, clinical factors such as previous history of eclampsia, symptoms of the disease, parity, history of pregnancy loss, gestational age, and antenatal care attendance were not significantly associated with the mode of delivery, even after adjustments were made for confounders, as shown in Table 3. In contrast, the method of the initiation of labour was statistically associated with the mode of delivery, as reported in Table 4.

Maternal blood pressures and laboratory test results were not associated with mode of delivery, as indicated in Table 5. Furthermore, as shown in Table 6, maternal complications such as haemorrhagic stroke, HELLP syndrome, and AKI were not associated with the mode of delivery.

In Table 7, factors such maternal history of chronic hypertension, symptoms, history of pregnancy loss, antenatal care attendance, and birth weights were not associated with the risk of newborn admission to the NBU, even after adjustments were made for confounders. In contrast, parity was significantly associated with the risk of newborn admission to the NBU. After adjustments were made for confounders, infants from multiparous women had 7.6-fold increased odds of being admitted to the NBU $(p=0.003,95 \% \mathrm{CI}=$ 2.0-28.6).

In addition, Table 8 represents NBU and maternal management during the course of the disease. The mode of delivery, indication of $\mathrm{C}$-section, and method of labour initiation were significantly associated with the risk of admission to the NBU. Similarly, infants born through caesarean section had a 4.7 -fold increase of being admitted to the NBU $(p=0.020,95 \%$ $\mathrm{CI}=1.3-17.1)$. Eclampsia as an indication of Csection increased the risk of admission to the NBU 4.3-fold ( $p=0.031,95 \% \mathrm{CI}=1.1-16.1)$. Additionally,

Table 2 Maternal socio-demographic characteristics and mode of delivery, using Fisher Exact test or chi-square test

\begin{tabular}{|c|c|c|c|c|c|c|c|c|}
\hline \multirow[t]{3}{*}{ Variables } & \multicolumn{4}{|c|}{ Mode of delivery } & \multirow[t]{3}{*}{$p$-value } & \multirow[t]{3}{*}{ OR } & \multirow[t]{3}{*}{$p$-value } & \multirow[t]{3}{*}{$95 \% \mathrm{Cl}$} \\
\hline & \multicolumn{2}{|c|}{ Vagina $(n=24)$} & \multicolumn{2}{|c|}{ Caesarean $(n=29)$} & & & & \\
\hline & No. & $\%$ & No. & $\%$ & & & & \\
\hline \multicolumn{9}{|l|}{ Maternal age group } \\
\hline$<20$ years ${ }^{\#}$ & 3 & 12.5 & 7 & 24.1 & ${ }^{M C} C_{p}=0.466$ & - & - & - \\
\hline 20-34 years & 17 & 70.8 & 16 & 55.2 & & 0.4 & 0.240 & $0.1-1.8$ \\
\hline $35-44$ years & 4 & 16.7 & 6 & 20.7 & & 0.6 & 0.640 & $0.1-4.1$ \\
\hline \multicolumn{9}{|l|}{ Education level } \\
\hline Low education level & 3 & 12.5 & 9 & 31.0 & 0.068 & 8.0 & $0.029^{*}$ & $1.2-51.5$ \\
\hline Secondary & 13 & 54.2 & 17 & 58.6 & & 3.5 & 0.105 & $0.8-15.8$ \\
\hline Tertiary ${ }^{\#}$ & 8 & 33.3 & 3 & 10.3 & & - & - & - \\
\hline \multicolumn{9}{|l|}{ Marital status } \\
\hline Married ${ }^{\#}$ & 17 & 70.8 & 13 & 44.8 & 0.057 & - & - & - \\
\hline Single & 7 & 29.2 & 16 & 55.2 & & 2.9 & 0.061 & $0.9-9.4$ \\
\hline \multicolumn{9}{|l|}{ Health insurance } \\
\hline Yes $^{\#}$ & 13 & 54.2 & 12 & 41.4 & 0.353 & - & - & - \\
\hline No & 11 & 45.8 & 17 & 58.6 & & 1.7 & 0.355 & $0.6-4.9$ \\
\hline Employees $^{\circledast}$ & 19 & 79.2 & 22 & 75.9 & 0.775 & - & - & - \\
\hline Unemployed & 5 & 20.8 & 7 & 24.1 & & 1.2 & 0.775 & $0.3-4.4$ \\
\hline \multicolumn{9}{|l|}{ Residence location } \\
\hline Rural & 21 & 87.5 & 26 & 89.7 & $\mathrm{FE}_{p}=1.000$ & 1.2 & 0.8 & $0.2-6.8$ \\
\hline Urban $^{\#}$ & 3 & 12.5 & 3 & 10.3 & & - & - & - \\
\hline
\end{tabular}

MC Monte Carlo, FE Fisher Exact

$p p$ value for association between different categories

$O R$ Odds ratio, $C I$ Confidence interval, $L L$ Lower limit, UL Upper Limit

*: Statistically significant at $p \leq 0.05$

$\#$ : no $p$-value 
Table 3 Mode of delivery and clinical characteristics, using Fisher Exact test or chi-square test

\begin{tabular}{|c|c|c|c|c|c|c|c|c|}
\hline \multirow[t]{3}{*}{ Clinical Characteristics } & \multicolumn{4}{|c|}{ Mode of delivery } & \multirow[t]{3}{*}{$p$-value } & \multirow[t]{3}{*}{ OR } & \multirow[t]{3}{*}{$p$-value } & \multirow[t]{3}{*}{$95 \% \mathrm{Cl}$} \\
\hline & \multicolumn{2}{|c|}{ Vaginal $(n=24)$} & \multicolumn{2}{|c|}{ Caesarean $(n=29)$} & & & & \\
\hline & No. & $\%$ & No. & $\%$ & & & & \\
\hline \multicolumn{9}{|l|}{ Medical History } \\
\hline None $^{\#}$ & 23 & 95.8 & 29 & 100.0 & $\mathrm{FE}_{p}=0.453$ & - & - & - \\
\hline Chronic hypertension & 1 & 4.2 & 0 & 0.0 & & - & - & - \\
\hline \multicolumn{9}{|l|}{ Symptoms } \\
\hline Epigastric pain & 9 & 37.5 & 13 & 44.8 & 0.590 & 1.4 & 0.590 & $0.4-4.1$ \\
\hline Coma & 4 & 16.7 & 1 & 3.4 & $\mathrm{FE}_{p}=0.164$ & 0.2 & 0.136 & $0.0-1.7$ \\
\hline Lower Limbs oedema & 10 & 41.7 & 8 & 27.6 & 0.281 & 0.5 & 0.284 & $0.2-1.7$ \\
\hline Headache & 16 & 66.7 & 18 & 62.1 & 0.728 & 0.8 & 0.728 & $0.3-2.5$ \\
\hline Blurred vision & 1 & 4.2 & 5 & 17.2 & $\mathrm{FE}_{p}=0.204$ & 4.8 & 0.167 & $0.5-44.2$ \\
\hline Convulsions & 20 & 83.3 & 28 & 96.6 & $\mathrm{FE}_{p}=0.164$ & 5.6 & 0.136 & $0.6-53.9$ \\
\hline \multicolumn{9}{|l|}{ Obstetric history } \\
\hline Nulliparous & 11 & 45.8 & 12 & 41.4 & 0.745 & 0.8 & 0.745 & $0.3-2.5$ \\
\hline Multiparous ( $\leq 4$ births) & 9 & 37.5 & 16 & 55.2 & 0.200 & 2.1 & 0.202 & $0.7-6.2$ \\
\hline Grand-Multiparous ( $\geq 5 b$ ) & 4 & 16.7 & 1 & 3.4 & $\mathrm{FE}_{p}=0.164$ & 0.2 & 0.136 & $0.0-1.7$ \\
\hline \multicolumn{9}{|l|}{ History of pregnancy loss } \\
\hline Yes & 3 & 12.5 & 5 & 17.2 & $\mathrm{FE}_{p}=0.715$ & 1.5 & 0.633 & $0.3-6.8$ \\
\hline $\mathrm{No}^{\#}$ & 21 & 87.5 & 24 & 82.8 & & - & - & - \\
\hline \multicolumn{9}{|l|}{ Gestational age } \\
\hline$\leq 28$ week & 4 & 16.7 & 0 & 0.0 & ${ }^{M C} c_{p}=0.075$ & - & - & - \\
\hline 28-33 weeks & 7 & 29.2 & 14 & 48.3 & & 1.0 & 0.853 & $0.2-4.4$ \\
\hline 34-37 weeks & 8 & 33.3 & 5 & 17.2 & & 0.3 & 0.141 & $0.0-1.5$ \\
\hline 38-40 weeks \# & 3 & 12.5 & 7 & 24.1 & & - & - & - \\
\hline LMP unknown & 2 & 8.3 & 3 & 10.3 & & 0.6 & 0.699 & $0.1-6.1$ \\
\hline \multicolumn{9}{|c|}{ Gestational period at time of enrollment } \\
\hline Intrapartum \# & 1 & 4.2 & 0 & 0.0 & $\mathrm{FE}_{p}=0.453$ & - & - & - \\
\hline Postpartum & 23 & 95.8 & 29 & 100.0 & & - & - & - \\
\hline \multicolumn{9}{|l|}{ ANC visit attendance } \\
\hline Yes & 22 & 91.7 & 27 & 93.1 & $\mathrm{FE}_{p}=1.000$ & 1.2 & 0.844 & $0.2-9.4$ \\
\hline No\# & 2 & 8.3 & 2 & 6.9 & & - & - & - \\
\hline
\end{tabular}

ANC antenatal care

initiation of labour, either spontaneous or induced were not statistically associated with increased risk of admission to the NBU (see Table 8).

Birth weights and perinatal deaths were not statistically associated with the mode of delivery, as shown in Table 9. Similarly, perinatal deaths were not associated with birth weights, as indicated in Table 10. Finally, the multivariate logistic regression showed that parity, especially multiparty, increased the risk of perinatal adverse outcomes $\left(p=0.004^{*}\right.$, $\mathrm{OR}=9.1,95 \% \mathrm{CI}=2.0-40.8)$. Eclampsia as indication for $\mathrm{C}$-section was not found to increase the risk of adverse perinatal outcome, as show in Table 11.

\section{Discussion}

The optimal mode of delivery in women with eclampsia remains controversial in the modern practice of obstetrics and gynaecology. In this study, the caesarean delivery rate was slightly higher than that of women who had normal vaginal delivery. This contrasts with the findings from the study done by Priti Kumari and colleagues, in which the rate of vaginal delivery was higher than that of caesarean delivery [9]. However, in most studies across the world, caesarean section delivery has been repeatedly reported to be higher in women with eclampsia [10-12]. The plausible explanation for the difference is that in most protocols, including ours, with respect to 
Table 4 Mode of delivery and maternal management, using Fisher Exact test or chi-square test

\begin{tabular}{|c|c|c|c|c|c|c|c|c|}
\hline \multirow[t]{3}{*}{ Variables } & \multicolumn{4}{|c|}{ Mode of delivery } & \multirow[t]{3}{*}{$p$-value } & \multirow[t]{3}{*}{ OR } & \multirow[t]{3}{*}{$p$-value } & \multirow[t]{3}{*}{$95 \% \mathrm{Cl}$} \\
\hline & \multicolumn{2}{|c|}{ Vaginal $(n=24)$} & \multicolumn{2}{|c|}{ Caesarean $(n=29)$} & & & & \\
\hline & No. & $\%$ & No. & $\%$ & & & & \\
\hline \multicolumn{9}{|l|}{ Facility of ANC visit } \\
\hline No ANC visit" & 2 & 8.3 & 2 & 6.9 & \multirow[t]{7}{*}{${ }^{\mathrm{MC}} p=0.243$} & - & - & - \\
\hline Teaching \&Referral Hosp & 1 & 4.2 & 0 & 0.0 & & - & - & - \\
\hline County referral Hospital & 4 & 16.7 & 0 & 0.0 & & - & - & - \\
\hline Sub-county Hospital & 3 & 12.5 & 3 & 10.3 & & 1.0 & 1.000 & $0.1-12.6$ \\
\hline Health centre & 9 & 37.5 & 17 & 58.6 & & 1.9 & 0.557 & $0.2-15.7$ \\
\hline Private Hospital & 1 & 4.2 & 1 & 3.4 & & 1.0 & 1.000 & $0.0-29.8$ \\
\hline Dispensary & 4 & 16.7 & 6 & 20.7 & & 1.5 & 0.733 & $0.1-15.5$ \\
\hline \multicolumn{9}{|l|}{ Mode of admission } \\
\hline From home ${ }^{\#}$ & 12 & 50.0 & 12 & 41.4 & \multirow[t]{2}{*}{${ }^{\mathrm{FE}} p=0.587$} & - & - & - \\
\hline Transferred & 12 & 50.0 & 17 & 58.6 & & 1.4 & 0.531 & $0.5-4.2$ \\
\hline \multicolumn{9}{|l|}{ Treatment of HTN } \\
\hline Yes & 5 & 20.8 & 5 & 17.2 & \multirow[t]{2}{*}{$\mathrm{FE}_{p}=1.000$} & 0.8 & 0.740 & $0.2-3.1$ \\
\hline $\mathrm{No}^{\#}$ & 19 & 79.2 & 24 & 82.8 & & - & - & - \\
\hline \multicolumn{5}{|l|}{ Medications } & \multicolumn{4}{|l|}{${ }^{M C} p=1.000$} \\
\hline Anticonvulsants ${ }^{\#}$ & 4 & 16.7 & 4 & 13.8 & & - & - & - \\
\hline Multiples drugs & 20 & 83.3 & 25 & 86.2 & & 1.3 & 0.771 & $0.3-5.6$ \\
\hline \multicolumn{9}{|l|}{ Labour initiation } \\
\hline None $e^{\#}$ & 0 & 0.0 & 17 & 58.6 & \multirow{2}{*}{$\begin{array}{l}{ }^{M C} p \\
<0.001^{*}\end{array}$} & & & \\
\hline Spontaneous & 15 & 62.5 & 12 & 41.4 & & & & \\
\hline \multicolumn{9}{|l|}{ Induction: } \\
\hline Cytotec & 4 & 16.7 & 0 & 0.0 & & - & - & - \\
\hline Foley catheter & 1 & 4.2 & 0 & 0.0 & & & & \\
\hline Foley catheter+ Cytotec & 4 & 16.7 & 0 & 0.0 & & & & \\
\hline
\end{tabular}

ANC antenatal care

the management of eclampsia, it is recommended that delivery should occur within $12 \mathrm{~h}$ following seizure(s), and only pregnant women admitted in the active phase of labour or with favourable Bishop scores are allowed to progress within the $12 \mathrm{~h}$ if the foetal status is preserved. Additionally, the extensive use of cardiotogram (CTG) machines to monitor labour and the lack of consensus on the interpretation of the tracing have widely contributed to an increased rate of caesarean delivery [13-15]. Another aspect that could explain the increased rate of $\mathrm{C}$-section delivery in eclamptic mothers is the panic attitude of midwives during seizer(s), while most of today's midwives do not agree to monitor the labour of women with eclampsia. Experience and good exposure in the field, as well as evidence-based practice of the art of obstetrics in resource-limited settings, may curve the trends of caesarean delivery among eclamptic mothers.

Socio-demographic factors such as maternal age, education level, occupation, healthcare insurance coverage, and geographic location were not significantly associated with mode of delivery. This finding contrasts with those of previous studies in which maternal age, educational level, parity, household socioeconomic status, rural residence location, and household level of education were associated with caesarean section delivery $[16,17]$. However, low maternal education increased the risk of caesarean delivery among affected women. This could be due to the easy accessibility of comprehensive emergency obstetric care, including caesarean section. We also noticed that some of these patients were operated on at county hospitals and were referred for further management of persistent seizures after delivery.

Clinical factors, including symptoms of the disease, parity, history of pregnancy loss, antenatal care attendance and facility attended for ANC, mode of admission, treatment of hypertension, and medications received during seizures, were not associated with the mode of delivery. Begun $\mathrm{N}$ and colleagues reported similar findings [18]. This could be explained by the good patient 
Table 5 Mode of delivery and maternal BPs and laboratory results, using Fisher Exact test or chi-square test

\begin{tabular}{|c|c|c|c|c|c|c|c|c|}
\hline \multirow[t]{3}{*}{ Variables } & \multicolumn{4}{|c|}{ Mode of delivery } & \multirow[t]{3}{*}{$p$-value } & \multirow[t]{3}{*}{ OR } & \multirow[t]{3}{*}{$p$-value } & \multirow[t]{3}{*}{$95 \% \mathrm{Cl}$} \\
\hline & \multicolumn{2}{|c|}{ Vaginal $(n=24)$} & \multicolumn{2}{|c|}{ Caesarean $(n=29)$} & & & & \\
\hline & No. & $\%$ & No. & $\%$ & & & & \\
\hline \multicolumn{9}{|l|}{ Blood pressures } \\
\hline$<140 / 90 \mathrm{mmHg}^{\#}$ & 2 & 8.3 & 5 & 17.2 & $\mathrm{FE}_{p}=0.436$ & - & - & - \\
\hline$\geq 140 / 90 \mathrm{mmHg}$ & 22 & 91.7 & 24 & 82.8 & & 0.4 & 0.350 & $0.077-2.483$ \\
\hline \multicolumn{9}{|l|}{ Proteinuria } \\
\hline Trace $^{\#}$ & 1 & 4.2 & 6 & 20.7 & $\mathrm{MC}_{p}=0.133$ & - & - & - \\
\hline $1+$ & 6 & 25.0 & 2 & 6.9 & & 6.0 & 0.165 & $0.478-75.34$ \\
\hline $3+$ & 13 & 54.2 & 17 & 58.6 & & 0.3 & 0.309 & $0.040-2.769$ \\
\hline $4+$ & 4 & 16.7 & 4 & 13.8 & & 1.3 & 0.737 & $0.274-6.240$ \\
\hline \multicolumn{9}{|l|}{ Platelet } \\
\hline$\geq 150.10^{9} / /$ & 19 & 79.2 & 23 & 79.3 & ${ }^{M C} C_{p}=0.694$ & 0.6 & 0.585 & $0.100-3.672$ \\
\hline$\leq 100.10^{9} / /^{\#}$ & 2 & 8.3 & 4 & 13.8 & & - & - & - \\
\hline$\leq 50.10^{9} / 1$ & 3 & 12.5 & 2 & 6.9 & & 0.3 & 0.383 & $0.028-.028$ \\
\hline \multicolumn{9}{|c|}{ Peripheral blood smear } \\
\hline Normal ${ }^{\#}$ & 21 & 87.5 & 29 & 100 & $\mathrm{FE}_{p}=0.086$ & - & - & - \\
\hline Abnormal & 3 & 12.5 & 0 & 0.0 & & - & - & - \\
\hline \multicolumn{9}{|l|}{ AST/ALT } \\
\hline$<70 \mathrm{IU} / \mathrm{I}^{\#}$ & 21 & 87.5 & 26 & 89.7 & $\mathrm{FE}_{p}=1.000$ & - & - & - \\
\hline$\geq 70 \mathrm{IU} / \mathrm{I}$ & 3 & 12.5 & 3 & 10.3 & & 1.2 & 0.806 & $0.226-6.781$ \\
\hline \multicolumn{9}{|l|}{ Serum bilirubin } \\
\hline Normal ${ }^{\#}$ & 22 & 91.7 & 27 & 93.1 & $\mathrm{FE}_{p}=1.000$ & - & - & - \\
\hline Increased & 2 & 8.3 & 2 & 6.9 & & 1.2 & 0.844 & $0.160-9.431$ \\
\hline \multicolumn{9}{|l|}{ LDH } \\
\hline$<600 \mathrm{IU} / \mathrm{I}^{\#}$ & 22 & 91.7 & 27 & 93.1 & ${ }^{\mathrm{FE}} p=1.000$ & - & - & - \\
\hline$\geq 600 \mathrm{IU} / \mathrm{I}$ & 2 & 8.3 & 2 & 6.9 & & 0.8 & 0.844 & $0.106-6.261$ \\
\hline \multicolumn{9}{|l|}{ Creatinine } \\
\hline$\leq 80 \mathrm{mmol} / \mathrm{I}^{\#}$ & 19 & 79.2 & 26 & 89.7 & $\mathrm{FE}_{p}=0.444$ & - & - & - \\
\hline$>80 \mathrm{mmol} / \mathrm{l}$ & 5 & 20.8 & 3 & 10.3 & & 2.3 & 0.297 & $0.485-10.73$ \\
\hline
\end{tabular}

$A S T$ aspartate transaminase, $A L T$ alanine transaminase, $L D H$ L-lactate dehydrogenase

Table 6 Mode of delivery and maternal outcomes

\begin{tabular}{|c|c|c|c|c|c|c|c|c|}
\hline \multirow[t]{3}{*}{ Variables } & \multicolumn{4}{|c|}{ Mode of delivery } & \multirow[t]{3}{*}{$\mathrm{FE}_{\mathrm{p}}$} & \multirow[t]{3}{*}{ OR } & \multirow[t]{3}{*}{$p$-value } & \multirow[t]{3}{*}{$95 \% \mathrm{C}$} \\
\hline & \multicolumn{2}{|c|}{ Vaginal $(n=24)$} & \multicolumn{2}{|c|}{ Caesarean $(n=29)$} & & & & \\
\hline & No. & $\%$ & No. & $\%$ & & & & \\
\hline \multicolumn{9}{|l|}{ Maternal outcome } \\
\hline ICU admission & 0 & 0.0 & 3 & 10.3 & 0.242 & - & - & - \\
\hline Recovery ${ }^{\#}$ & 24 & 100.0 & 29 & 100 & - & - & - & - \\
\hline \multicolumn{9}{|l|}{ Complications } \\
\hline Kidney injury & 5 & 20.8 & 3 & 10.3 & 0.444 & 0.4 & 0.297 & $0.1-2.1$ \\
\hline Incomplete HELLP synd & 3 & 12.5 & 3 & 10.3 & 1.000 & 1.2 & 0.806 & $0.2-6.9$ \\
\hline Stroke & 0 & 0.0 & 1 & 3.4 & 1.000 & - & - & - \\
\hline True HELLP syndrome & 5 & 20.8 & 6 & 20.7 & 1.000 & 0.9 & 0.990 & $0.3-3.8$ \\
\hline
\end{tabular}


Table 7 NBU admission and maternal clinical characteristics and birth weight, using Fisher Exact test or chi-square test

\begin{tabular}{|c|c|c|c|c|c|c|c|c|}
\hline \multirow[t]{3}{*}{ Clinical Characteristics } & \multicolumn{4}{|c|}{ NBU admission } & \multirow[t]{3}{*}{$p$-value } & \multirow[t]{3}{*}{ OR } & \multirow[t]{3}{*}{$p$-value } & \multirow[t]{3}{*}{$95 \% \mathrm{Cl}$} \\
\hline & \multicolumn{2}{|c|}{ No $(n=35)$} & \multicolumn{2}{|c|}{ Yes $(n=18)$} & & & & \\
\hline & No. & $\%$ & No. & $\%$ & & & & \\
\hline \multicolumn{9}{|l|}{ Medical History } \\
\hline None $^{\#}$ & 34 & 97.1 & 18 & 100.0 & $\mathrm{FE}_{p}=1.000$ & - & - & - \\
\hline Chronic HTN & 1 & 2.9 & 0 & 0.0 & & - & - & - \\
\hline \multicolumn{9}{|c|}{ Clinical presentation or complaint } \\
\hline Epigastric pain & 15 & 42.9 & 7 & 38.9 & 0.781 & 0.8 & 0.781 & $0.3-2.7$ \\
\hline Coma & 4 & 11.4 & 1 & 5.6 & $\mathrm{FE}_{p}=0.651$ & 0.5 & 0.498 & $0.0-4.4$ \\
\hline Lower limbs oedema & 12 & 34.3 & 6 & 33.3 & 0.945 & 0.9 & 0.945 & $0.3-3.2$ \\
\hline Headache & 21 & 60.0 & 13 & 72.2 & 0.380 & 1.7 & 0.382 & $0.5-5.9$ \\
\hline Blurred vision & 4 & 11.4 & 2 & 11.1 & $\mathrm{FE}_{p}=1.000$ & 0.9 & 0.972 & $0.2-5.9$ \\
\hline Convulsions & 31 & 88.6 & 17 & 94.4 & $\mathrm{FE}_{p}=0.651$ & 0.5 & 0.498 & $0.0-4.4$ \\
\hline \multicolumn{9}{|l|}{ Obstetric history } \\
\hline Nulliparous & 19 & 54.3 & 4 & 22.2 & $0.026^{*}$ & - & - & - \\
\hline Multiparous ( $\leq 4$ births) & 11 & 31.4 & 14 & 77.8 & $0.001^{*}$ & 6.0 & $0.008^{*}$ & $1.6-23.0$ \\
\hline Grand-Multiparous ( $\geq 5$ b) & 5 & 14.3 & 0 & 0.0 & $\mathrm{FE}_{p}=0.153$ & - & - & - \\
\hline \multicolumn{9}{|l|}{ History of pregnancy loss } \\
\hline Yes & 4 & 11.4 & 4 & 22.2 & $\mathrm{FE}_{p}=0.421$ & 0.5 & 0.306 & $0.1-2.1$ \\
\hline $\mathrm{No}^{\#}$ & 31 & 88.6 & 14 & 77.8 & & - & - & - \\
\hline \multicolumn{9}{|c|}{ Gestational period at time of enrollment } \\
\hline Intrapartum \# & 1 & 2.9 & 0 & 0.0 & $\mathrm{FE}_{p}=1.000$ & - & - & - \\
\hline Postpartum & 34 & 97.1 & 18 & 100.0 & & - & - & - \\
\hline \multicolumn{9}{|l|}{ ANC visit attendance } \\
\hline Yes & 31 & 88.6 & 18 & 100.0 & $\mathrm{FE}_{p}=0.287$ & - & - & - \\
\hline $\mathrm{No}^{\#}$ & 4 & 11.4 & 0 & 0.0 & & - & - & - \\
\hline Birth weight & & & & & ${ }^{M C} p=0.364$ & & & \\
\hline$<1000 \mathrm{~g}$ & 1 & 2.9 & 3 & 16.7 & & 5.0 & 0.239 & $0.3-72.8$ \\
\hline $1000 \mathrm{~g}-1500 \mathrm{~g}$ & 12 & 34.3 & 5 & 27.8 & & 0.7 & 0.687 & $0.1-4.1$ \\
\hline $1600 \mathrm{~g}-2400 \mathrm{~g}$ & 17 & 48.6 & 7 & 38.9 & & 0.7 & 0.661 & $0.1-3.7$ \\
\hline $2500 \mathrm{~g}-4000 \mathrm{~g}^{\#}$ & 5 & 14.3 & 3 & 16.7 & & - & - & - \\
\hline
\end{tabular}

response to treatment. Moreover, evidence recommends that the pregnant mother with eclampsia should be stabilized before making decisions regarding delivery [19]. However, the goal of stabilizing the patient with medications is not to conserve the pregnancy but to allow for better assessment and the ability to determine the optimal and safest mode of delivery within a reasonable amount of time.

All patients from this study received magnesium sulfate as anticonvulsant. To date, magnesium sulfate (MgSO4) is first line medication and preferred anticonvulsant to stabilize pregnant mother with eclampsia [20]. It is a lifesaving drug, which slows neuromuscular conduction and decreases the central nerves system irritability by triggering cerebral vasodilation, thus reducing ischemia generated by cerebral vasospasm during an eclamptic event [20]. The advantages of using MgSO4 as drug of choice are not only limited to prevent primary and recurrent maternal seizures; but it reduces maternal and perinatal mortality and morbidity in pregnant women with pre-eclampsia and eclampsia [20-22]. It plays a role of neuroprotection by reducing the risk of cerebral palsy in grow-restricted foetus and preterm below 30 weeks of gestation $[21,22]$. In Kenya, MgSO4 is an essential medication available at all different levels of care. The national guidelines for quality obstetrics and perinatal care recommend the administration of MgSO4 to all pregnant women with preeclampsia with features of severity and eclamptic women before being transferred to the high level of care [23]. In the protocol of $\mathrm{RMBH}$, the administration of intravenous magnesium sulfate to all pregnant women with preeclampsia, 
Table 8 NBU admission and maternal management, using Fisher Exact test or chi-square test

\begin{tabular}{|c|c|c|c|c|c|c|c|c|}
\hline \multirow[t]{3}{*}{ Variables } & \multicolumn{4}{|c|}{ NBU admission } & \multirow[t]{3}{*}{$p$-value } & \multirow[t]{3}{*}{ OR } & \multirow[t]{3}{*}{$p$-value } & \multirow[t]{3}{*}{$95 \% \mathrm{Cl}$} \\
\hline & \multicolumn{2}{|c|}{ No $(n=35)$} & \multicolumn{2}{|c|}{ Yes $(n=18)$} & & & & \\
\hline & No. & $\%$ & No. & $\%$ & & & & \\
\hline \multicolumn{9}{|l|}{ Facility of ANC visit } \\
\hline None $^{\#}$ & 4 & 11.4 & 0 & 0.0 & \multirow[t]{7}{*}{${ }^{M C} p=0.354$} & - & - & - \\
\hline Teaching \&Referral Hosp & 1 & 2.9 & 0 & 0.0 & & - & - & - \\
\hline County referral Hosp & 2 & 5.7 & 2 & 11.1 & & - & - & - \\
\hline Sub-county Hosp & 5 & 14.3 & 1 & 5.6 & & - & - & - \\
\hline Health centre & 14 & 40.0 & 12 & 66.7 & & - & - & - \\
\hline Private Hosp & 1 & 2.9 & 1 & 5.6 & & - & - & - \\
\hline Dispensary & 8 & 22.9 & 2 & 11.1 & & - & - & - \\
\hline \multicolumn{9}{|l|}{ Mode of admission } \\
\hline From home ${ }^{\#}$ & 15 & 42.9 & 9 & 50.0 & \multirow[t]{2}{*}{0.621} & - & - & - \\
\hline Transferred & 20 & 57.1 & 9 & 50.0 & & 0.8 & 0.621 & $0.2-2.3$ \\
\hline \multicolumn{9}{|l|}{ Treatment of HTN } \\
\hline Yes & 7 & 20.0 & 3 & 16.7 & \multirow[t]{2}{*}{$\mathrm{FE}_{p}=1.000$} & 0.8 & 0.769 & $0.2-3.6$ \\
\hline $\mathrm{No}^{\#}$ & 28 & 80.0 & 15 & 83.3 & & - & - & - \\
\hline \multicolumn{5}{|l|}{ Medications } & \multicolumn{4}{|l|}{${ }^{M C} C_{p}=0.701$} \\
\hline Anticonvulsants ${ }^{\#}$ & 6 & 17.1 & 2 & 11.1 & & - & - & - \\
\hline Multiples drugs & 29 & 82.9 & 16 & 88.9 & & 1.655 & 0.564 & $0.3-9.2$ \\
\hline \multicolumn{9}{|l|}{ Mode of delivery } \\
\hline Vaginal $^{\#}$ & 20 & 57.1 & 4 & 22.2 & \multirow[t]{2}{*}{$0.016^{*}$} & - & - & - \\
\hline Caesarean & 15 & 42.9 & 14 & 77.8 & & 4.7 & $0.020^{*}$ & $1.3-17.1$ \\
\hline \multicolumn{9}{|l|}{ Indication of C-section } \\
\hline$N / A^{\#}$ & 20 & 57.1 & 4 & 22.2 & \multirow{4}{*}{$\begin{array}{l}{ }^{M C} C_{p=} \\
0.012^{*}\end{array}$} & - & - & - \\
\hline Eclampsia & 14 & 40.0 & 12 & 66.7 & & 4.3 & $0.031^{*}$ & $1.1-16.1$ \\
\hline NRFS & 0 & 0.0 & 2 & 11.1 & & 0.9 & - & - \\
\hline Arrested disorders & 1 & 2.9 & 0 & 0.0 & & - & - & - \\
\hline \multicolumn{9}{|l|}{ Labour initiation } \\
\hline $\mathbf{N} / \mathbf{A}(C-$ section $)$ & 8 & 22.9 & 9 & 50.0 & \multirow[t]{6}{*}{ MCp $=0.028^{*}$} & 3.9 & $0.036^{*}$ & $1.1-14.7$ \\
\hline Spontaneous $s^{\#}$ & 21 & 60.0 & 6 & 33.3 & & - & - & - \\
\hline Induction: & & & & & & & & $0.9-120.5$ \\
\hline Cytotec & 1 & 2.9 & 3 & 16.7 & & 10.5 & 0.059 & - \\
\hline Cytotec+ F. catheter & 1 & 2.9 & 0 & 0.0 & & - & - & \\
\hline Foley catheter & 4 & 11.4 & 0 & & & - & - & \\
\hline \multicolumn{9}{|c|}{ Spontaneous vs induction of labour: } \\
\hline Spontaneous ${ }^{\#}$ & 21 & 60.0 & 6 & 33.3 & \multirow[t]{2}{*}{0.066} & - & - & - \\
\hline Other labour induction & 14 & 40.0 & 12 & 66.7 & & 3.0 & 0.066 & $0.9-9.9$ \\
\hline
\end{tabular}

HTN hypertension, C-section caesarean section, N/A not applicable, NRFS non-reassuring foetal status

presenting features of severity, and eclamptic mothers is mandatory. The loading dose, $4 \mathrm{~g}$ for $20 \mathrm{~min}$, followed by maintenance intravenous dose of $1 \mathrm{~g}$ per hour. The treatment with $\mathrm{MgSO} 4$ is maintained until $24 \mathrm{~h}$ postdelivery or from 24-h after the last seizure. The toxicity of magnesium sulfate was monitor through patients' vital signs (oxygen saturation, deep tendon reflexes, level of consciousness, and urinary input and output) as outlined in the national and WHO guidelines [20,23].

In this study, majority of cases, with very elevated blood pressure, $\geq 160 \mathrm{mmHg}$ systolic pressure and $\geq 110$ $\mathrm{mmHg}$ diastolic pressure received both anticonvulsant and antihypertensive. This approach is described in several guidelines $[23,24]$. In RMBH protocol, the first line 
Table 9 Mode of delivery, birth weights, and perinatal deaths, using Fisher Exact test or chi-square test

\begin{tabular}{|c|c|c|c|c|c|c|c|c|}
\hline \multirow[t]{3}{*}{ Variables } & \multicolumn{4}{|c|}{ Mode of delivery } & \multirow[t]{3}{*}{$p$-value } & \multirow[t]{3}{*}{ OR } & \multirow[t]{3}{*}{$p$-value } & \multirow[t]{3}{*}{$95 \% \mathrm{Cl}$} \\
\hline & \multicolumn{2}{|c|}{ Vaginal $(n=24)$} & \multicolumn{2}{|c|}{ Caesarean $(n=29)$} & & & & \\
\hline & No. & $\%$ & No. & $\%$ & & & & \\
\hline \multicolumn{9}{|l|}{ Perinatal death } \\
\hline Yes & 4 & 16.7 & 1 & 3.4 & $\mathrm{FE}_{p}=0.164$ & 0.2 & 0.136 & $0.0-1.7$ \\
\hline $\mathrm{No}^{\#}$ & 20 & 83.3 & 28 & 96.6 & & - & - & - \\
\hline \multicolumn{9}{|l|}{ Birth weights } \\
\hline$<1000 \mathrm{~g}$ & 4 & 16.7 & 0 & 0.0 & ${ }^{M C} C_{p}=0.140$ & - & - & - \\
\hline $1000 \mathrm{~g}-1500 \mathrm{~g}$ & 8 & 33.3 & 9 & 31.0 & & 0.675 & 0.654 & $0.121-3.767$ \\
\hline $1600 \mathrm{~g}-2400 \mathrm{~g}$ & 9 & 37.5 & 15 & 51.7 & & 1.000 & 1.000 & $0.192-5.222$ \\
\hline $2500 \mathrm{~g}-4000 \mathrm{~g}^{\#}$ & 3 & 12.5 & 5 & 17.2 & & - & - & - \\
\hline
\end{tabular}

antihypertensive severe preeclampsia and eclampsia remains intravenous labetalol $20 \mathrm{mg}$. However, other institutions' guidelines and protocol recommend hydralazine as first line antihypertensive [25]. Hydralazine is a central vasodilator that has been used in severe hypertension and preeclampsia in pregnancy [26]. It is administered as a 5- to 10 -mg dose IV or IM every 15 min up to a maximum dose of $20 \mathrm{mg}$ IV or $30 \mathrm{mg}$ IM $[25,26]$. The onset of action hydralazine is 10 to $20 \mathrm{~min}$ $[25,26]$. In contrast, labetalol is a nonselective, competitive beta-adrenergic and a selective, competitive alpha1adrenergic blocking agent [26]. The recommended dose of labetalol is $20 \mathrm{mg}$ over slow-infusion IV for a maximum dosage of $200 \mathrm{mg}$ [23]. There are 2 potential advantages of labetalol over hydralazine, including quicker onset of action ( $5 \mathrm{~min}$ ) and less risk for reflex tachycardia $[25,26]$. The mechanism of action of labetalol is exerted by reduction of peripheral vascular resistance without compromising blood flow to the brain and peripheral, coronary, or renal systems [25]. These reasons explain the choice of labetalol as first-line treatment of severe preeclampsia and eclampsia at $\mathrm{RMBH}$. The goal of treating acute severe hypertension in preeclampsia/ eclampsia is crucially to prevent cerebrovascular and cardiovascular events as well as maternal death. In this study, few patients who had slightly elevated blood pressure, $\leq 140 \mathrm{mmHg}$ systolic and $\leq 90 \mathrm{mmHg}$ diastolic, or nearly normal blood pressure were managed with $\mathrm{MgSO} 4$ only, up to $24 \mathrm{~h}$ post-delivery or $24 \mathrm{~h}$ after the last seizure. The reason of withholding antihypertensive in patients with nearly normal BPs is supported the double effective role of MgSO4: prevention and/ or control of seizures and lowering total peripheral vascular resistance (calcium antagonist).

The method of initiation of labour was significantly associated with the mode of delivery, where induction of labour (IOL) with Cytotec alone, Foley catheter alone or a combination of the Foley catheter and Cytotec showed reduced morbidity related to caesarean delivery. Pregnant women in whom labour was initiated artificially had an unfavourable cervix (poor Bishop score). However, the duration of labour was not recorded, but the absence of emergency caesarean section delivery among those women showed that vaginal delivery was achieved within a reasonable time of $12 \mathrm{~h}$. In a randomized study conducted by Seal SL and colleagues on eclamptic patients, IOL was preferably the safest mode of delivery and did not increase the risk of caesarean section delivery [27]. Therefore, the authors of the current study recommend IOL in eclamptic mothers to achieve vaginal delivery, even with an unfavourable cervix. This has a reasonable implication and advantage in terms of cost and the prevention of primary caesarean section with good outcomes.

Table 10 Perinatal death by birth weights

\begin{tabular}{|c|c|c|c|c|c|c|c|c|}
\hline \multirow[t]{3}{*}{ Variables } & \multicolumn{4}{|c|}{ Perinatal death } & \multirow[t]{3}{*}{$M C_{p}$} & \multirow[t]{3}{*}{ OR } & \multirow[t]{3}{*}{$p$-value } & \multirow[t]{3}{*}{$95 \% \mathrm{Cl}$} \\
\hline & \multicolumn{2}{|c|}{ No $(n=48)$} & \multicolumn{2}{|c|}{ Yes $(n=5)$} & & & & \\
\hline & No. & $\%$ & No. & $\%$ & & & & \\
\hline \multicolumn{9}{|l|}{ Birth weights } \\
\hline$<1000 \mathrm{~g}$ & 4 & 8.3 & 0 & 0.0 & 0.896 & - & - & - \\
\hline $1000 \mathrm{~g}-1500 \mathrm{~g}$ & 15 & 31.3 & 2 & 40.0 & & 1.0 & - & - \\
\hline $1600 \mathrm{~g}-2400 \mathrm{~g}$ & 21 & 43.8 & 3 & 60.0 & & 1.0 & - & - \\
\hline $2500 \mathrm{~g}-4000 \mathrm{~g}^{\#}$ & 8 & 16.7 & 0 & 0.0 & & - & - & - \\
\hline
\end{tabular}


Table 11 Multivariate analysis Logistic regression for NBU admission

\begin{tabular}{lllll}
\hline Variables & Sig. & OR & \multicolumn{2}{c}{$\mathbf{9 5 \%} \mathrm{Cl}$} \\
\cline { 5 - 6 } & & & LL & UL \\
\hline Multiparity & $0.004^{*}$ & 9.1 & 2.0 & 40.8 \\
Eclampsia as indication for C-section & 0.323 & 2.4 & 0.4 & 13.4 \\
\hline
\end{tabular}

LL Lower limit, UL Upper Limit

Regarding maternal outcomes, there was no maternal death reported in this study. This finding contrasts with previous studies conducted in a similar context of resource-limited settings of sub-Saharan Africa and other developing countries, where maternal mortality from eclampsia was higher [18-30]. This is the result of a clear and tight protocol for the management of the disease, as well as interdisciplinary care. For example, patients who were in critical condition after delivery were admitted to the ICU, where they were managed with a multidisciplinary team that included obstetricians, nephrologists, anaesthesiologists, neurologists and neurosurgeons, and trained nurses in intensive care. Such management approaches, as well as ICUs, are widely lacking in most resource-limited settings in sub-Saharan Africa. Therefore, improving maternal and newborn care in developing countries cannot be achieved on paper but rather through investment in health infrastructure and staff. Moreover, the World Health Organization is defined as a standard roadmap for improving maternal and newborn care in health facilities [31].

Maternal complications from the disease included HELLP syndrome, acute kidney injury, and stroke, which were not associated with the mode of delivery. To date, HELLP syndrome is classified either complete (true) or incomplete HELL syndrome [8]. The diagnostic criteria are based on Tenessee classification as described by Sibai for "true" HELL syndrome, and the Mississippi-Triple class system [8]. In the particular context of this study, patients with both complete and incomplete HELLP syndrome were involved, considering eclampsia as lifethreatening disease or complication of preeclampsia.

Given the current evidence, caesarean section delivery is discouraged with HELLP syndrome and AKI due to the risk of uncontrolled bleeding and poor elimination of anaesthetic drugs [8,32-34]. The incidence of these complications was also less frequent than that reported in other studies [1-5]. However, the reason for prompt delivery in eclampsia is to prevent serious maternal complications, including death. Townsend and colleagues state that the only cure for preeclampsia and eclampsia is the delivery of the placenta, while all other approaches merely serve to manage symptoms and stabilize the mother [6]. In line with this, the Riley Mother and Baby Hospital (RMBH) protocol has made "delivery" the gold standard for the management of eclampsia, regardless of gestational age and foetal status. Any attempt toward the conservative management of eclampsia is not permitted. To date, if several studies have agreed on nonconservative management and prompt delivery, controversy regarding the mode of delivery has persisted. However, in the current study, even if there was no maternal death, caesarean section delivery was not associated with better maternal outcomes in terms of morbidity and ICU admission. This is congruent with the findings of a randomized controlled study performed by Seal SL and colleagues, who found that $\mathrm{C}$-section was not associated with better outcomes [27].

Maternal convulsive seizures are also dangerous for the foetus. However, perinatal outcomes and maternal clinical characteristics, especially previous history of eclampsia, symptoms of the disease, history of pregnancy loss, antenatal care attendance and facility attended for ANC, mode of admission, treatment of HTN, and medications during eclamptic seizures, were not associated with the risk of infants being admitted to the NBU. This is because eclampsia is associated with transient maternal hypoxic status, which has minimal transient effects on the foetus [19]. In settings where there is a CTG machine, the effects of maternal hypoxia on the foetus during seizures are shown by transient reduced variability and bradycardia for up to 20 min after maternal seizures [19]. Persistent reduced variability may be related to the effects of drugs used to control and stabilize maternal conditions and/or persistent maternal hypoxia during status eclampticus [6]. In this study, parity, mode of delivery, indication of $\mathrm{C}$-section delivery, and method of initiation of labour were significantly associated with the risk of infants' admission to the NBU. Regarding parity, Melese MF and colleagues had similar findings, especially in nulliparous and multiparous patients [35, 36]. This could be related to individual factors such as the severity of the disease, drug effects, prematurity, and/or mode of delivery. In addition, caesarean section delivery increased the risk of newborns' admission to the nursery, especially those for whom the indication for C-section was eclampsia, whereas IOL significantly reduced the risk of NBU admission. Vaginal delivery slightly increased the rate of perinatal death. Indeed, majority of perinatal were fresh stillbirths and macerated stillbirths. The fresh stillbirths occurred in mothers who were admitted with severe foetal bradycardia, and in the doctors' judgement, C-section delivery could not help. There was 1 fresh stillbirth from $\mathrm{C}$-section where the indication was eclampsia. Surgical skills during the procedure, "difficult extraction", and the effects of anaesthesia, prematurity were major contributors for that specific case. Therefore, caesarean section delivery is not associated with better perinatal outcomes. It should be performed 
for obstetric reasons, defined as inability to accomplish a vaginal delivery within a specified time, governed by maternal condition. However, due to observational nature of the study, authors acknowledge the limitations of the study, which can not be used to demonstrate causes of observed adverse outcomes.

\section{Conclusion}

Emergency caesarean section delivery offers no benefit for maternal and perinatal outcomes in women with eclampsia. Although observational in nature, this study showed that it is possible to achieved vaginal delivery through induction of labour in eclamptic mothers with unfavourable Bishop scores. Knowing eclampsia is lifethreatening disease or complications for pregnant women, this study showed that maternal mortality can be reduced or prevented with prompt and effective care.

\section{Limitations and recommendations}

This study was conducted in one tertiary hospital, and the sample size was too small to be generalized. In addition, this was not a randomized clinical trial; therefore, the evidence that it provides can not be generalized. Further multi-centres and randomized study with a large sample size is needed to interrogate current findings.

\section{Abbreviations}

ANC: Antenatal care; ICU: Intensive care unit; IOL: Induction of labour

\section{Supplementary Information}

The online version contains supplementary material available at https://doi. org/10.1186/s12884-021-03875-6.

Additional file 1: Table 1.1. Socio-demographic characteristics. Table 2.1. Maternal clinical characteristics. Table 2.2. Maternal BPs and laboratory results. Table 2.3. Management.

Additional file 2.

\section{Acknowledgements}

The authors acknowledge the maternal-foetal medicine fellows of Moi University and the residents, midwives and nurses of Riley Mother and Baby Hospital for their support during the research period.

\section{Authors' contributions}

All authors made significant contributions to the manuscript. K.I. and P.A. drafted the proposal; A.M. contributed to the research design; O.E., R.M, A.C, and A.M. critically polished the proposal; K.I. trained and supervised the data collection; K.I. and P.A. approved the completeness of data collection; and A.M., O.E., K.I., R.M, A.C and P.A. validated the analysis. P.A. drafted the manuscript; O.E. critically polished the manuscript; and A.M., O.E., R.M., K.I., A.C, and P.A. validated the manuscript. All authors have read and approved the final version of the manuscript. Therefore, all authors agree to be accountable for the content of the work.

\section{Funding}

No external funds were received.

\section{Availability of data and materials}

All data generated or analysed during this study are included in this published article [and its supplementary information files].

\section{Declarations}

Ethics approval and consent to participate

This study was approved by the Institutional Research Ethical Committee of Moi Teaching and Referral Hospital-Moi University School of Medicine (IRECMTRH-MUSOM) on 14 June 2019 under the number FAN:0003344. All participants signed informed consent to participate in this study.

Consent for publication

Not applicable.

\section{Competing interests}

There are no competing interests.

\section{Author details}

'Reproductive Health, Moi Teaching\& Referral Hospital, PO Box 3-30100, Nandi road, Eldoret, Kenya. ${ }^{2}$ Department of Reproductive Health, Moi University School of Medicine, P. O. Box 4606-30100, Eldoret, Kenya. ${ }^{3}$ Department of Behavioural Sciences, Moi University School of Medicine, P.O. Box 4606-30100, Eldoret, Kenya.

Received: 17 August 2020 Accepted: 13 May 2021

Published online: 24 June 2021

\section{References}

1. Essiben F, Wandji YD, Ngo Um ME, Mve KV, Dohbit SJS, Ojong SA, et al, Eclampsia in African milieu, Yaounde-Cameroon: epidemiology, seasonal variations and treatment regimen. Obstet Gynecol Int J. 2019;10(3):176-83.

2. Magley M and Hinson MR. Eclampsia. [Updated 2020 Feb 1]. In: StatPearls [Internet]. Treasure Island (FL): StatPearls Publishing; 2020 Jan-https://www. ncbi.nlm.nih.gov/books/NBK554392. Accessed 29 July, 2020.

3. Eclampsia. US Medscape. 2019. https://emedicine.medscape.com/article/253 960-overview. Accessed 12 July, 2020.

4. Vousden N, Lawley E, Seed PT, Gidiri MF, Goudar S, Sandall J, et al. CRADLE Trial Collaborative Group. Incidence of eclampsia and related complications across 10 low-and middle-resource geographical regions: Secondary analysis of a cluster randomised controlled trial. PLoS Med. 2019;16(3): e1002775 https://doi.org/10.1371

5. Lam MTC, Dierking E. Intensive care unit issues in eclampsia and HELLP syndrome. Int J Crit Illn Inj Sci. 2017;7(3):136-41. https://doi.org/10.4103/ IJCIIS.IJCIIS_33_17.

6. Townsend R, O'Brien P, Khalil A. Current best practice in the management of hypertensive disorders in pregnancy. Integr Blood Press Control. $2016 \mathrm{Jul}$ 27;9:79-94. https://doi.org/10.2147//BPC.S77344.

7. Mulaki, A., \& Muchiria, S. (2019). Kenya Health System Assessment. http:// www.healthpolicyplus.com/ns/pubs/11328-11600_KenyaHSAReport.pdf. Accessed 10 October 2020

8. Haram K, Svendsen E, Abildgaard U. The HELLP syndrome: clinical issues and management. A review. BMC Pregnancy Childbirth. 2009;9(1):8. https:// doi.org/10.1186/1471-2393-9-8.

9. Kumari P, Singh S, Khatun S. Comparative study of vaginal delivery and caesarean section in antepartum eclampsia at tertiary care hospital. Int J Reprod Contracept Obstet Gynecol. 2017;6(2):457-60. https://doi.org/10.182 03/2320-1770.jijrog20170007.

10. Maji B, Samanta S, Banerjee S, Mullick TH, Saharay S, Sarkar D. Clinicoepidemiological profile of eclampsia patients admitted in an urban tertiary care hospital of West Bengal: a record based study. Int I Community Med Public Health. 2018;5(6):2416. https://doi.org/10.18203/2394-6040.ijcmph201 82169.

11. Saeed G, Wajid R, Dar AY. Maternal mortality in eclampsia after cesarean section versus vaginal delivery. Ann King Edward Med Univ. 2017;23(4):4515. https://doi.org/10.21649/journal.akemu/2017/23.4.451.455.

12. Rabiu KA, Adewunmi AA, Ottun TA, Akinlusi FM, Adebanjo AA, Alausa TG. Risk factors for maternal mortality associated with eclampsia presenting at a Nigerian tertiary hospital. Int J Womens Health. 2018;10:715. https://doi. org/10.2147/JJWH.S178729.

13. Paterno MT, McElroy K, Regan M. Electronic fetal monitoring and cesarean birth: a scoping review. Birth. 2016;43(4):277-84. https://doi.org/10.1111/ birt.12247. 
14. Barstow C, Gauer R, Jamieson B. How does electronic fetal heart rate monitoring affect labor and delivery outcomes? Clin Inquiries. 2010;(MU): 2010 J Fam Pract. 2010 November;59(11):653a-653b.

15. Alfirevic Z, Gyte GM, Cuthbert A, Devane D. Continuous cardiotocography (CTG) as a form of electronic fetal monitoring (EFM) for fetal assessment during labour. Cochrane Database Syst Rev. 2017;2. https://doi.org/10.1 002/14651858.CD006066.pub3.

16. Manyeh AK, Amu A, Akpakli DE, Williams J, Gyapong M. Socioeconomic and demographic factors associated with caesarean section delivery in southern Ghana: evidence from INDEPTH network member site. BMC Pregnancy Childbirth. 2018;18(1):405. https://doi.org/10.1186/s12884-018-2039-z.

17. Oliveira RR, Melo EC, Novaes ES, Ferracioli PL, Mathias TA. Factors associated to caesarean delivery in public and private health care systems. Rev Esc Enferm USP. 2016;50(5):733-40. https://doi.org/10.1590/S0080-6234201 60000600004.

18. Begum N, Jahan S, Ganguly S, Anwar BR. Feto-maternal outcome of vaginal delivery and caesarean section in Eclamptic patients. J Dhaka Med Coll. 2015;24(2):92-8.

19. Cipolla MJ, Kraig RP. Seizures in women with preeclampsia: mechanisms and management. Fetal Matern Med Rev. 2011;22(02):91-108. https://doi. org/10.1017/S0965539511000040.

20. World Health Organization. (2014). WHO recommendations for prevention and treatment of pre-eclampsia and eclampsia: implications and actions (No. WHO/RHR/14.17). World Health Organization. Database: https://www. who.int/reproductivehealth/publications/maternal_perinatal_health/progra m-action-eclampsia/en/. Accessed 10 October 2020.

21. Antenatal Magnesium Sulphate for Neuroprotection Guideline Development Panel. (2010). Antenatal Magnesium Sulphate Prior to Preterm Birth for Neuroprotection of the Fetus, Infant, and Child 2010: National Clinical Practice Guidelines. Australian Research Centre for Health of Women and Babies, the University of Adelaide. Database: https://cdn.auckland.ac. nz/assets/liggins/docs/Antenatal\%20magnesium\%20sulphate\%20prior\%2 0to\%20preterm\%20birth\%20for\%20neuroprotection\%20of\%20the\%2 Ofetus, $\% 20$ infant $\% 20 \& \% 20$ child,\%20National\%20clinical\%20practice $\% 2$ Oguidelines.pdf .Accessed 11 October 2020.

22. Stockley EL, Ting JY, Kingdom JC, McDonald SD, Barrett JF, et al. Intrapartum magnesium sulfate is associated with neuroprotection in growth-restricted fetuses. Am J Obstet Gynecol. 2018;219(6):606.e1-8. https://doi.org/10.1016/ j.ajog.2018.09.010

23. Ministry of Health Kenya. National Guidelines for quality obstetrics and perinatal care. Database. 2012; http://guidelines.health.go.ke:8000/media/Na tional_Guidelines_for_Quality_Obstetrics_and_Perinatal_Care.pdf . Accessed 11 October 2020.

24. Townsend $\mathrm{R}$, O'Brien $\mathrm{P}$, Khalil A. Current best practice in the management of hypertensive disorders in pregnancy. Integrated Blood Pressure Control. 2016:9:79-94. https://doi.org/10.2147/IBPC.S77344.

25. Khan A, Hafeez S, Nasrullah FD. Comparison of hydralazine and labetalol to lower severe hypertension in pregnancy. Pakistan J Med Sci. 2017;33(2):46670. https://doi.org/10.12669/pjms.332.12243.

26. Dutta DC, Konar H. JP Medical Ltd. Chapter. Hypertensive disorder in pregnancy. In: DC Dutta's textbook of gynecology; 2014. p. 219-40.

27. Seal SL, Ghosh D, Kamilya G, Mukherji J, Hazra A, Garain P. Does route of delivery affect maternal and perinatal outcome in women with eclampsia? A randomized controlled pilot study. Am J Obstet Gynecol. 2012;206(6):484e1-.e7. https://doi.org/10.1016/j.ajog.2012.04.009.

28. Mahran A, Fares H, Elkhateeb R, Ibrahim M, Bahaa H, Sanad A, et al. Risk factors and outcome of patients with eclampsia at a tertiary hospital in Egypt. BMC Pregnancy Childbirth. 2017;17(1):435. https://doi.org/10.1186/s12 884-017-1619-7.

29. Kullima A, Kawuwa MB, Audu BA, Usman H, Geidam AD. A 5-year review of maternal mortality associated with eclampsia in a tertiary institution in northern Nigeria. Ann Afr Med. 2009;8(2). https://doi.org/10.4103/1596-3519. 56233.

30. Noubiap JJ, Bigna JJ, Nyaga UF, Jingi AM, Kaze AD, Nansseu JR, et al. The burden of hypertensive disorders of pregnancy in Africa: a systematic review and meta-analysis. J Clin Hypertens. 2019;21(4):479-88. https://doi. org/10.1111/jch.13514.

31. World Health Organization. Standards for improving quality of maternal and newborn care in health facilities. World Health Organization - 2016 - www. who.int. Access 30 July, 2020
32. Rimaitis K, Grauslyte L, Zavackiene A, Baliuliene V, Nadisauskiene R, Macas A. Diagnosis of HELLP syndrome: a 10-year survey in a perinatology Centre Int. J Environ Res Public Health. 2019;16(1):109. https://doi.org/10.3390/ijerph1 6010109.

33. Jim B, Garovic VD. Acute kidney injury in pregnancy. Semin Nephrol. 2017 Jul;37(4):378-85. https://doi.org/10.1016/j.semnephrol.2017.05.010.

34. Liu Y, Ma X, Zheng J, Liu X, Yan T. Pregnancy outcomes in patients with acute kidney injury during pregnancy: a systematic review and metaanalysis. BMC Pregnancy Childbirth. 2017;17(1):235. https://doi.org/10.1186/ s12884-017-1402-9.

35. Melese MF, Badi MB, Aynalem GL. Perinatal outcomes of severe preeclampsia/eclampsia and associated factors among mothers admitted in Amhara region referral hospitals, north West Ethiopia, 2018. BMC Res Notes. 2019;12(1):1-6.

36. Pannu D, Das B, Hazari P. Shilpa. Maternal and perinatal outcome in eclampsia and factors affecting the outcome: a study in north Indian population. Int J Reprod Contracept Obstet Gynecol. 2014;3(2):347-51. https://doi.org/10.5455/2320-1770.ijrcog20140612.

\section{Publisher's Note}

Springer Nature remains neutral with regard to jurisdictional claims in published maps and institutional affiliations.
Ready to submit your research? Choose BMC and benefit from:

- fast, convenient online submission

- thorough peer review by experienced researchers in your field

- rapid publication on acceptance

- support for research data, including large and complex data types

- gold Open Access which fosters wider collaboration and increased citations

- maximum visibility for your research: over $100 \mathrm{M}$ website views per year

At BMC, research is always in progress.

Learn more biomedcentral.com/submissions 